\title{
REVIEW
}

\section{Is normal pressure hydrocephalus a valid concept in 2002? A reappraisal in five questions and proposal for a new designation of the syndrome as "chronic hydrocephalus"}

\author{
P Bret, J Guyotat, J Chazal
}

J Neurol Neurosurg Psychiatry 2002;73:9-12

The authors question the current validity of the traditional concept of normal pressure hydrocephalus (NPH) as it was described by Adams and Hakim in 1965. The classic features of the disease are addressed. It is concluded that most of the historical statements made three decades ago need to be revised. Especially, the term "normal pressure" hydrocephalus probably does not match the actual manometric profile of patients with NPH. Similarly, the terms "curable" and "reversible" dementia are inadequate to designate the mental alterations of NPH. That NPH is non-specific to the adult population is also stressed, since it may be not uncommonly encountered in paediatrics, especially in an implanted shunt malfunction. The term "chronic hydrocephalus" without reference to cerebrospinal fluid pressure and to the age of the patient is proposed instead of $\mathrm{NPH}$, which seems out of step with current knowledge of the pressure profile and with the diagnosis and decision making context in patients with so called NPH.

See end of article for authors' affiliations

....................

Correspondence to: Dr P Bret, Service de Neurochirurgie B, Hôpital Neurologique et Neurochirurgical Pierre Wertheimer, 59 boulevard Pinel, CHU de Lyon, 69394 Lyon Cédex 3, France;

philippe.bret@chu-lyon.fr or Dr Chazal;

jchazal@

chu-clermontferrand.fr

Received 3 April 2001 In revised form 17 January 2002

Accepted 8 February 2002
$\mathrm{N}$ ormal pressure hydrocephalus (NPH) was described in 1965 by Hakim and Adams as a new syndrome in three patients showing a characteristic clinical triad of altered mentation, gait difficulties, and sphincter disturbances together with ventricular dilatation in air studies and normal pressure of the cerebrospinal fluid (CSF) at lumbar puncture. ${ }^{1}$ This apparently paradoxical condition has prompted a considerable number of studies aimed at explaining the pathophysiological background of the disease and at identifying the best candidates for CSF shunting surgery.

At the beginning of the 21 st century, many controversies remain about the nosographic concept of the disease, its pathophysiology, diagnostic tests, and the most reliable predictors of a good response after shunting. In 1990, we published a comprehensive report on this topic and we proposed that the new designation "chronic hydrocephalus" be used instead of the NPH, which seemed inadequate. ${ }^{2}$

In 2002, it is interesting to question the current validity of Adams and Hakim's historical concept by addressing the five following issues:
1. Was NPH actually a newly discovered disease when reported in 1965 by Adams and Hakim?

2. Is CSF pressure really normal in patients with NPH?

3. Is NPH really a cause of curable dementia?

4. Is NPH specific to the adult and elderly population?

5. Is CSF shunt the only treatment modality?

\section{WAS NPH ACTUALLY A NEWLY DISCOVERED CONDITION WHEN REPORTED BY ADAMS AND HAKIM IN 1965 ?}

The answer to this somewhat provocative question is negative. Several papers published before 1965 clearly addressed this problem in patients showing the apparent paradox of progressive symptomatic hydrocephalus without overt signs of intracranial hypertension..$^{3-11}$ Especially, a pioneering paper by Riddoch ${ }^{8}$ provided as early as 1936 a description of the syndrome that was closely similar to that proposed by Adams and Hakim three decades later: "The clinical picture was one of slowly progressive dementia. All this indicates that the main explanation of the absence of headache, vomiting and papilledema lies in the very gradual obstruction to the CSF circulation. The absence of increased pressure in the ventricles and on lumbar puncture supports this view." ${ }^{\prime \prime}$ Strikingly similar descriptions are also available in other early contributions, such as those by McHugh ${ }^{6}$ and by Messert and Baker, ${ }^{7}$ with a special mention of relief of symptoms after shunting in the latter.

\section{IS CSF PRESSURE REALLY NORMAL IN PATIENTS WITH NPH?}

This question is of utmost importance because it addresses the pathophysiological background of the syndrome. It should be remembered that the historical labelling "normal pressure" hydrocephalus was based on the finding that all three reported patients showed low CSF pressures at lumbar puncture, namely 150, 180, and $160 \mathrm{~mm}$ $\mathrm{H}_{2} \mathrm{O} .{ }^{1}$ It is now widely recognised that a single,

Abbreviations: CSF, cerebrospinal fluid; $C T$, computed tomography; ICP, intracranial pressure; MRI, magnetic resonance imaging; $\mathrm{NPH}$, normal pressure hydrocephalus 
limited in time, CSF pressure measurement by lumbar puncture yields a poor estimation of the real intracranial pressure (ICP) profile of patients with NPH.

Moreover, there is an abundant literature based on ICP monitoring that acknowledges that CSF pressure may actually not be normal in this population. ${ }^{22-15}$ In this view, the presence of numerous $\mathrm{B}$ waves on prolonged CSF pressure recording indicates a general trend to episodic high ICP levels, which was interpreted by some authors as a favourable predictor of response after shunting..$^{12-16}$ Although the predictive value of CSF infusion tests remains debatable, ${ }^{17} 18$ measurements of resistance to outflow and of the pressurevolume index showed that, in the case of a sudden increase of ICP, compensatory mechanisms were altered and easily overwhelmed in patients with NPH. ${ }^{2}{ }^{19} 20$

Additionally, there is clinical evidence from daily practice that makes questionable the current use of the term NPH: only a few specialised institutions have gained expertise in routine CSF infusion tests. In most neurosurgical centres, the decision to use shunting in such patients is undertaken on the basis of their clinical and computed tomography (CT) or magnetic resonance imaging (MRI) presentation without assessment of their CSF pressure.

The importance of the clinical and CT parameters in decision making has been clearly confirmed in the above mentioned report based on 243 cases $^{2}$ and in other recent contributions. ${ }^{21}{ }^{22}$ Specifically, it has been shown that good results after shunting can reasonably be expected in patients showing a ventricular dilatation with a frontal horn ratio exceeding 0.50 on CT studies along with one or more of the following criteria:

- Presence of a clearly identified etiology;

- Predominant gait difficulties with mild or absent cognitive impairment;

- Substantial improvement after CSF withdrawal (CSF tap test);

- Normal sized or occluded sylvian fissures and cortical sulci on CT or MRI;

- Absent or moderate white matter lesions on MRI.

The presence at the first evaluation of such favourable parameters justifies by itself the decision for shunting and makes the use of ancillary tests unnecessary, including the CSF dynamic tests, which are invasive and rely to a large extent on the operator's expertise. In patients lacking favourable criteria, a 3-5 day external lumbar drainage has been reported to be a reliable predictor of outcome after shunting. ${ }^{23-25}$ The predictive value of CSF hydrodynamics assessed by $\mathrm{T} 2$ weighted images and cine phase contrast MRI in patients with NPH is being evaluated. ${ }^{26-29}$

Difficulties in the nosographic designation of the syndrome are acknowledged by the number of alternative terms that have been proposed, which cannot be listed here. Since the early recognition of the syndrome, it has been suggested that the term NPH might not be the most appropriated for the condition..$^{31}$ Because the traditional terminology matches neither the usual conditions of decision making nor the real ICP profile of patients with so called NPH, we proposed in 1990 to designate this syndrome "chronic hydrocephalus". ${ }^{2}$

\section{IS NPH REALLY A CAUSE OF CURABLE DEMENTIA?}

Unfortunate terminologies such as "hydrocephalic dementia" or "curable dementia" have been used extensively to designate the mental disorders of NPH. ${ }^{32-34}$ Such confusing terms have generated the widespread myth that some forms of "true" dementia can be cured by shunt surgery, this view being apparently supported by some biopsy or necropsy findings showing that degenerative or ischaemic brain lesions may be associated with ventricular dilatation. ${ }^{35-38}$ This erroneous belief abusively led to extensive application of shunt operations in demented patients, with uniformly devastating results; this may be an explanation for the disappointment among the neurosurgical community during the first few years that followed Adams and Hakim's publication. ${ }^{39}$ Still, nowadays, neurosurgeons are occasionally requested to use shunting in such patients based on the argument that "they have nothing to lose".

Although a specific psychometric profile is difficult to define in $\mathrm{NPH}$, psychometric studies have widely documented the fact that patients with NPH did not fit the criteria of degenerative (Alzheimer =type) or arteriosclerotic dementia. ${ }^{20-42}$ Although psychometric tests may not differentiate NPH from other types of subcortical mental alterations, they have proved helpful in distinguishing subcortical from cortical cognitive deficits. Patients with NPH exhibit subcortical=type mental deficits including forgetfulness, decreased attention, inertia, and mental slowness with a pattern of memory impairment that differs from that of Alzheimer's disease and other cortical encephalopathies. ${ }^{22} 4143$ The differential diagnosis with Alzheimer=type dementia is further supported by the fact that patients with NPH do not exhibit the "aphasia-apraxia-agnosia syndrome", which belongs to the picture of cortical dementia.

True dementia, as defined in the Diagnostic and statistical manual of mental disorders, third edition, revised, ${ }^{44}$ does not belong to the clinical triad and "demented patient" should definitely be excluded from clinical descriptions of NPH. When massive intellectual loss is present in the clinical presentation, other diagnoses should be considered and shunt surgery should be refused even in cases where CT studies illustrate some degree of ventricular dilatation, which is also a common finding in demented patients. In such cases, the presence of significant hippocampal atrophy on MRI studies has been reported to be an important neuroimaging criterion for the diagnosis of Alzheimer's disease. ${ }^{45}$

\section{IS NPH SPECIFIC TO THE ADULT AND ELDERLY POPULATION?}

In other words, is there a paediatric counterpart to adult NPH? This question raises the problem of the normal ICP level in children, which remains a debatable matter. It is generally agreed that there is a relation between ICP and the age of children, with ICP values progressively increasing from subatmospheric levels in the neonate to a range of $20-70 \mathrm{~mm} \mathrm{H}_{2} \mathrm{O}$ during infancy and ultimately to its adult levels by the age of eight years. ${ }^{46-48}$

Several studies reported in the literature have shown that a condition comparable with NPH may not be uncommon in childhood. ${ }^{49-56}$

From a clinical standpoint, a paediatric form of the triad may be characterised as follows:

- Subtle mental deterioration manifested by poor or decreasing scholar performances;

- Anomalies of gait manifested either by walking retardation in infants or by repeated falling spells in older children;

- Anomalies of micturition with delayed bladder control, whose relation to hydrocephalus is frequently overlooked or ascribed to enuresis. Urodynamic evaluation of bladder dysfunction in hydrocephalic children has shown that a mechanism grossly similar to that found in adult patients was involved, namely a failure of the supraspinal detrusor inhibitory centres. ${ }^{49} 5758$

Paediatricians should be aware of the possible occurrence of slowly progressive symptomatic hydrocephalus in children. Especially, patients with shunt malfunction may show subtle deterioration of their psychointellectual performances without overt signs of intracranial hypertension. Such a condition 
may be misdiagnosed as a "shunt independent arrested hydrocephalus", overlooking the fact that hydrocephalus is still active and that shunt revision may be beneficial. ${ }^{49} 5059$

\section{IS CSF DIVERSION THE ONLY TREATMENT MODALITY?}

Despite several attempts to introduce non-shunt methods of treatment, alternatives to shunting remain marginal or even speculative. In most instances of suspected NPH, the crucial problem is still whether to shunt or not to shunt.

Ventriculoperitoneal shunts have become standard treatment although ventriculoatrial shunts are still a second line option in patients with a history of multiple laparotomies or with defective peritoneal CSF resorption. Although proposed as an attractive and safer modality, ${ }^{260}$ lumboperitoneal shunt has never gained widespread use in patients with NPH, probably because its application is strictly limited to proven communicating forms of hydrocephalus and because of the high rate of tonsillar herniation reported in patients with such a shunt implanted. ${ }^{61}$

Whatever the type of shunt, the major drawback of all shunting methods is the high rate of shunt related complications resulting in the highest morbidity in neurosurgical practice. Recent improvements in shunt technologies are aimed at reducing the incidence of technical failures and of siphon effect related complications of shunts. Technical refinements include antisiphon devices, ${ }^{62}$ flow controlled valves, ${ }^{63}$ and valves with adjustable pressure. ${ }^{64-66}$ The cost effectiveness of such devices compared with conventional hydrostatic valves is still under debate.

Besides the vast majority of patients with NPH, in whom shunt surgery is the only possible treatment, in a limited number of cases other modalities may be considered.

Curing a causative factor is seldom possible in secondary $\mathrm{NPH}$ but should be proposed in the few cases where CSF flow is compromised by intracranial tumours or malformations, without previous shunt implantation. ${ }^{2}$

Medical treatment of NPH includes acetazolamide and repeated lumbar punctures, which have occasionally yielded prolonged clinical improvement. ${ }^{6768}$ Although justified in patients with high surgical risks, conservative management usually results in mild and transient relief of symptoms and shunt surgery is ultimately required.

Except for rare cases of aqueductal stenosis related NPH, there has been little enthusiasm for third ventriculostomy in patients with NPH, mainly because hydrocephalus has been regarded in most instances as resulting from a communicating CSF circulation disorder. A recent contribution suggests that third ventriculostomy may be an attractive alternative to shunting, even in cases where the aqueduct is patent on imaging studies, in reducing the tissue stress to periventricular areas by reducing the transaqueductal pressure gradient. ${ }^{69}$ However, third ventriculostomy cannot be recommended as a first line treatment and its efficiency in patients with NPH requires further validation.

\section{CONCLUSION}

Some of the statements made by Adams and Hakim 35 years ago remain valid today. This is true for the clinical presentation since a majority of patients at diagnosis fit the criteria of the triad, with the notable reservation that the term "true" dementia is not attributable to its psychiatric component. It is also true that some carefully selected patients respond to shunting, which remains the standard today. However, an unacceptably high rate of shunt related complications justifies all attempts at promoting alternative methods of treatment.

On the other hand, it has become obvious that the other elements of the historical concept of NPH need to be revised. NPH should not be regarded as an age related disease specific to the adult and elderly population. A similar condition may be encountered during childhood, with a clinical presentation that does not differ basically from that of the adult and may be erroneously ascribed to "arrested hydrocephalus", which is a distinct condition. More important, the term NPH is questionable because it matches neither the real conditions of the current diagnosis-which is established in most institutions on the basis of the clinical and CT presentation only, without assessment of the ICP-nor the actual CSF manometric profile of such patients. This is acknowledged by the results of dynamic tests that showed a general trend to increased, albeit compensated, pressure levels or at least an inability of compensatory mechanisms to dampen a sudden increase of ICP in patients with NPH.

For these several reasons, we propose a more relevant nosographic designation for the NPH syndrome by renaming it "chronic hydrocephalus" without reference to age and CSF pressure. Chronic hydrocephalus is an active process that should be replaced in the sequence of events that result from failure of the circulatory resorptive mechanisms of the CSF. It may be regarded as an intermediate state of balance between uncompensated hypertensive hydrocephalus and asymptomatic hydrocephalus (in which compensatory systems are fully effective). As proved by follow up monitoring of shunting in patients, insertion of a shunt in those suffering from chronic hydrocephalus often provides a clinical cure without changes in their ventricular size. Shunting may therefore be regarded as an additional compensatory system allowing chronic hydrocephalus to turn in to asymptomatic hydrocephalus, which may be the only condition that really deserves the label NPH.

Competing interests: none declared

\section{Authors' affiliations}

P Bret, J Guyotat, Service de Neurochirurgie B, Hôpital Neurologique et Neurochirurgical Pierre Wertheimer, 59 boulevard Pinel, CHU de Lyon, 69394 Lyon Cédex 3, France

J Chazal, Service de Neurochirurgie, Hôpital Gabriel Montpied, CHU de Clermont-Ferrand, Place Henri Dunand, BP 69, 63003

Clermont-Ferrand, France

\section{REFERENCES}

1 Adams RD, Fisher CM, Hakim S, et al. Symptomatic occult hydrocephalus with "normal" cerebrospinal fluid pressure. N Engl J Med 1965;273:117-26

2 Bret P, Chazal J. L'hydrocéphalie chronique de l'adulte. Neurochirurgie 1990;36(suppl 1):1-159.

3 Foltz EL, Ward AA. Communicating hydrocephalus from subarachnoid bleeding. J Neurosurg 1956;13:546-66.

4 Kibler RF, Couch RSC, Crompton MR. Hydrocephalus in the adult following spontaneous subarachnoid hemorrhage. Brain $1961: 84: 45-61$.

5 Lhermitte J, Mouzon J. L'hydrocéphalie de l'adulte à forme paraplégique et à poussées successives. Rev Neurol 1942;74:63-5. 6 McHugh PR. Occult hydrocephalus. Q J Med 1964;33:297-312.

7 Messert B, Baker NH. Syndrome of progressive spastic ataxia and apraxia associated with occult hydrocephalus. Neurology 1966; 16:440-52.

8 Riddoch G. Progressive dementia without headaches or changes in the optic disks due to tumors of the third ventricle. Brain 1936;59:225-33.

9 Shulman K, Martin BF, Popoff N, et al. Recognition and treatment of hydrocephalus following spontaneous subarachnoid hemorrhage. J Neurosurg 1963;20:1040-9.

10 Wertheimer P, Dechaume J. Les hydrocéphalies de l'adulte. Rev Neurol 1950:82:405-51.

11 Yakovlev PI. Paraplegias of hydrocephalus clinical note and interpretation. Am J Ment Defic 1947;51:561-76.

12 Borgesen SE, Gjerris F. The predictive value of conductance to outflow of CSF in normal pressure hydrocephalus. Brain 1982;105:65-86.

13 Janny $\mathbf{P}$, Flori $B$, Georget $A M$, et al. La résistance à l'écoulement du LCR dans I'hydrocéphalie à pression normale. Rev Neurol 1975;131:211-7.

14 Symon L, Dorsch NWC. Use of long-term intracranial pressure measurement to assess hydrocephalic patients prior to shunt surgery. $J$ Neurosurg 1975;42:258-73.

15 Vorstrup S, Christensen J, Gjerris F, et al. Cerebral blood flow in patients with normal pressure hydrocephalus before ant after shunting. J Neurosurg 1987;66:379-87. 
16 Symon L, Dorsch NWC, Stephens RJ. Pressure waves in so-called low pressure hydrocephalus. Lancet 1972;ii:1291-2.

17 Boon AJW, Tans JTJ, Delwel EJ, et al. Dutch normal pressure hydrocephalus study: prediction of outcome after shunting by resistance to outflow of cerebrospinal fluid. J Neurosurg 1997;87:687-93.

18 Kostelianetz M, Nehen AM, Kaalund J. Cerebrospinal fluid outflow resistance measurements in the selection of patients for shunt surgery in the normal pressure hydrocephalus syndrome. A controlled trial. Acta Neurochir 1990;104:48-53.

19 Gierris F, Borgesen SE. Pathophysiology of the CSF circulation. In: Crockard A, Hayward R, Hoff J, eds. Neurosurgery: the scientific basis of clinical practice. Boston: Blackwell Scientific Publications 1992;1:146-75

20 Tans JTJ. Differentiation of normal pressure hydrocephalus and cerebral atrophy by computed tomography and spinal infusion test. J Neurol 1979:222:109-18.

21 Vanneste J, Augustijn P, Tan WF, et al. Shunting normal pressure hydrocephalus: the predictive value of combined clinical and CT data. $J$ Neurol Neurosurg Psychiatry 1993;56:251-6.

22 Vanneste J. Diagnosis and management of normal-pressure hydrocephalus. J Neurol 2000;247:5-14

23 Chen IH, Huang Cl, Liu HC, et al. Effectiveness of shunting in patients with normal pressure hydrocephalus predicted by temporary, controlled-resistance, continuous lumbar drainage: a pilot study. J Neurol Neurosurg Psychiatry 1994:57: 1430-2.

24 Haan J, Thomeer RTWM. Predictive value of temporary external lumbar drainage in normal pressure hydrocephalus. Neurosurgery 1988;22:388-91.

25 Hebb A, Cusimano MD. Idiopathic normal pressure hydrocephalus: a systematic review of diagnosis and outcome. Neurosurgery 2001;49:1166-86.

26 Bradley WG Jr, Scalzo D, Queralt J, et al. Normal pressure hydrocephalus: evaluation with cerebrospinal fluid flow measurements at MR imaging. Radiology 1996;198:523-9.

27 Egeler-Peerdeman SM, Barkhof F, Walchenbach R, et al. Cine phase-contrast MR imaging in normal pressure hydrocephalus patients: relation to surgical outcome. Acta Neurochir 1998;71(suppl):340-2.

28 Hakim R, Black PM. Correlation between lumbo-ventricular perfusion and MRI-CSF flow studies in idiopathic normal pressure hydrocephalus. Surg Neurol 1998:49:14-9.

29 Kim DS, Choi JU, Huh R, et al. Quantitative assessment of cerebrospinal fluid hydrodynamics using a phase-contrast cine MR image in hydrocephalus. Childs Nerv Syst 1999;15:461-7.

30 Ekstedt J, Friden H. CSF hydrodynamics especially in the adult hydrocephalus syndrome. In: Beks JWF, Bosch DA, Brock $M$, eds. Intracranial pressure III. Berlin: Springer-Verlag 1976:177-85.

31 Hakim S, Adams RD. The special clinical problem of symptomatic hydrocephalus with normal cerebrospinal fluid pressure. Observations on cerebrospinal fluid hydrodynamics. J Neurol Sci 1965;2:307-27.

32 Benson DF. Hydrocephalic dementia. Handbook of clinical neurology. In: Frederiks JAM, ed. Neurobehavioural disorders. Amsterdam: Elsevier Science Publishers BV, 1985;2:323-33.

33 Hill ME, Lougheed WM, Barnett HJ. A treatable form of dementia due to normal pressure communicating hydrocephalus. Can Med Assoc J 1967:97:1309-20.

34 Mc Hugh PR, Goodell H. Hydrocephalic dementia: differential diagnosis, psychometric tests and response to treatment. Neurology 1966;16:299

35 Akai K, Uchigasaki S, Tanaka U, et al. Normal pressure hydrocephalus. Neuropathological study. Acta Pathol Jpn 1987;37:97-110.

36 Di Rocco C, Di Trapani G, Maira G, et al. Anatomo-clinical correlations in normotensive hydrocephalus. Reports on 3 cases. J Neurol Sci 1977;33:437-52.

37 Jellinger K. Neuropathological aspects of dementias resulting from abnormal blood and CSF dynamics. Acta Neurol Belg 1976;76:83-102.

38 Newton H, Pickard JD, Weller RO. Normal pressure hydrocephalus and cerebrovascular disease: findings of post-mortem [letter]. J Neurol Neurosurg Psychiatry 1989;52:804.

39 Bannister CM. A report of 8 patients with low-pressure hydrocephalus treated by cerebrospinal fluid diversion with disappointing results. Acta Neurochir 1972;27:11-5

40 Vanneste JAL. Clinical and neuropsychological characteristics of normal pressure hydrocephalus: an observational study. In: Vanneste JAL. Normal pressure hydrocephalus [PhD thesis]. Rodopi: University of Amsterdam, 1991:53-62.

41 Vanneste JAL. Three decades of normal pressure hydrocephalus: are we wiser now? J Neurol Neurosurg Psychiatry 1994;57:1021-5.
42 Pillon B, Deweer B, Agid Y, et al. Explicit memory in Alzheimer's, Huntington's, and Parkinson's disease. Arch Neurol 1993;50:374-9.

43 Helkala EL, Laulumaa U, Soininen $\mathrm{H}$, et al. Recall and recognition memory in patients with Alzheimer's and Parkinson's diseases. Ann Neurol 1988;24:214-7.

44 Diagnostic and statistical manual of mental disorders, 3rd edn, revised. Washington: American Psychiatric Association, 1987.

45 Holodny AI, Waxman R, George AE, et al. MR differential diagnosis of normal-pressure hydrocephalus and Alzheimer disease: significance of perihippocampal features. ANNR Am J Neuroradiol 1998;19:813-9.

46 Di Rocco C, McLone DG, Shimoji T, et al. Continuous intraventricular cerebrospinal fluid recording in hydrocephalic children during wakefulness and sleep. J Neurosurg 1975;42:683-9.

$47 \mathrm{McC}$ cllough DC. A critical evaluation of continuous intracranial pressure monitoring in pediatric hydrocephalus. Childs Brain 1980;6:225-41.

48 Welch $\mathrm{K}$. The intracranial pressure in infants. J Neurosurg 1980;52:693-9.

49 Bret P, Chazal J. Chronic ("normal pressure") hydrocephalus in childhood and adolescence. A review of 16 cases and reappraisal of the syndrome. Childs Nerv Syst 1995;11:687-91.

50 Di Rocco C, Caldarelli M, Maira G, et al. The study of cerebrospinal fluid dynamics in apparently "arrested" hydrocephalus in children. Childs Brain 1977;3:359-74

51 Gordon N. Normal pressure hydrocephalus and arrested hydrocephalus. Dev Med Child Neurol 1977:19:540-3.

52 Hill A, Volpe JJ. Normal pressure hydrocephalus in the newborn. Pediatrics 1981;68:623-9.

53 Ingram TTS. Low pressure hydrocephalus [letter]. Dev Med Child Neurol $1971 ; 13: 676$.

54 Milhorat TH, Hammock MK. "Arrested" versus normal pressure hydrocephalus in children. Clin Proc Child Hosp Natl Med Cent 1972;28: 168-73

55 Stein BM, Fraser RA, Tenner MS. Normal pressure hydrocephalus: complication of posterior fossa surgery in children. Pediatrics 1972;49:50-8

56 Torkelson RD, Leibrock LG, Gustavson JL, et al. Neurological and neuropsychological effects of cerebrospinal fluid shunting in children with assumed arrested ("normal pressure") hydrocephalus. J Neurol Neurosurg Psychiatry 1985;48:799-806.

57 Ahlberg J, Norlen L, Blomstrand C, et al. Outcome of shunt operation on urinary incontinence in normal pressure hydrocephalus predicted by lumbar puncture. J Neurol Neurosurg Psychiatry 1988:51:105-8.

58 Wikkelso C, Andersson H, Blomstrand C, et al. The clinical effect of lumbar puncture in normal pressure hydrocephalus. I Neurol Neurosurg Psychiatry 1982;45:64-9.

59 Fried A, Shapiro K. Subtle deterioration in shunted childhood hydrocephalus. J Neurosurg 1986;65:211-6.

60 Brunon J, Motuo-Fotso M, Duthel R, et al. Traitement de l'hydrocéphalie chronique de l'adulte par dérivation lombo-péritonéale. Résultats et indications à propos de 82 observations. Neurochirurgie 1991;37:173-8.

61 Chumas PD, Armstrong DC, Drake JM, et al. Tonsillar herniation: the rule rather than the exception after lumboperitoneal shunting in the pediatric population. J Neurosurg 1993;78:568-73.

62 Aschoff A, Kremer P, Benesch C, et al. Overdrainage and shunt technology: a critical comparison of programmable, hydrostatic and variable resistance valves and flow reducing devices. Childs Nerv Syst 1995; 11:139-202

63 Sainte-Rose C, Hooven MD, Hirsch JF. A new approach in the treatment of hydrocephalus. J Neurosurg 1987;66:213-26.

64 Belliard H, Roux FX, Turak B, et al. La valve de dérivation Codman-Medos programmable. Bilan de 53 implantations chez 50 patients. Neurochirurgie 1996;42:139-46.

65 Black PM, Hakim R, Bailey NO. The use of the Codman-Medos programmable Hakim valve in the management of patients with hydrocephalus: illustrative cases. Neurosurgery 1994;34: $1110-3$.

66 Bret P, Guyotat J, Ricci AC, et al. Expérience clinique de la valve réglable Sophy® dans le traitement de l'hydrocéphalie de l'adulte. Une série de 147 cas. Neurochirurgie 1999:45:98-109.

67 Aimard G, Vighetto A, Gabet JY, et al. Acétazolamide: une alternative à la dérivation dans I'hydrocéphalie à pression normale? Résultats préliminaires.Rev Neurol 1990;146:437-9.

68 Elvidge AR, Branch CL, Thompson GB. Observations in a case of hydrocephalus treated with Diamox®. J Neurosurg 1957;14:628-38.

69 Mitchell P, Mathew B. Third ventriculostomy in normal pressure hydrocephalus. Br J Neurosurg 1999;13:382-5. 